\title{
PROPRIEDADES TERMODINÂMICAS A PARTIR DA VELOCIDADE DO SOM: CÁLCULO VIA REDES NEURAIS ARTIFICIAIS.
}

\author{
E. B. MELO, E. T. OLIVEIRA e T. D. MARTINS
}

Universidade Federal de São Paulo, Departamento de Ciências Exatas e da Terra. E-mail para contato: edis.unifesp@gmail.com; tdmartins@unifesp.br

\begin{abstract}
RESUMO - Para se obter propriedades termodinâmicas de uma determinada substância, equações complexas, e de difícil solução, precisam ser utilizadas. Além disso, às vezes muito tempo computacional é necessário na obtenção da solução final. Sendo assim, para superar esses desafios, o presente trabalho utilizou as redes neurais artificiais (RNAs). Tais redes, uma vez treinadas, podem ser usadas rapidamente para o cálculo em questão. Neste trabalho, utilizaram-se dados experimentais da água, disponíveis na literatura, para treinar RNAs visando calcular a densidade molar e a capacidade calorífica a pressão constante a partir da temperatura, pressão e velocidade do som. A topologia que mostrou melhor desempenho na etapa de treinamento foi a que possuía 20 e 30 neurônios nas suas duas camadas ocultas. Os resultados apresentaram erros médios de $0,7 \%$ e $0,1 \%$ para a capacidade calorífica e densidade, respectivamente. Na etapa de simulação, procurou-se avaliar o desempenho da RNA treinada com dados experimentais independentes daqueles que foram utilizados na etapa de treinamento. Nessa etapa, os erros foram de 3,21\% para a densidade e 3,22\% para a capacidade calorífica. Por meio destas análises, comprovou-se que as RNAs são uma ferramenta eficiente para o cálculo das propriedades termodinâmicas da água a partir da velocidade do som.
\end{abstract}

\section{INTRODUÇÃO}

O conhecimento das propriedades termodinâmicas das substâncias tem um papel fundamental nas aplicações práticas na Engenharia e também em outras áreas. A utilização dos valores de pressão, entropia, temperatura, capacidades caloríficas e calor latente de vaporização são necessários quando se deseja simular ou estudar um determinado processo dentro da Engenharia Química via balanços de massas e energia. No entanto, a dificuldade de se encontrar esses dados nas diversas literaturas disponíveis dificulta o andamento de diversos projetos.

Dentre as diversas propriedades termodinâmicas, a velocidade do som ainda é pouco explorada em projetos de Engenharia. Para a fase líquida, ela se relaciona diretamente com a densidade molar e a capacidade calorífica à pressão constante por meio de um sistema de equações diferenciais parciais. No entanto, para a fase vapor, as equações são diferentes e a relação se dá com a densidade molar e a capacidade calorífica à volume constante. Ou seja, é preciso saber em que região do diagrama de fases se está trabalhando antes de escolher qual 
conjunto de equações resolver. Além disso, a resolução desse sistema depende da aplicação de um método numérico que pode ser uma tarefa demorada, imprecisa e, que muitas vezes não traz o resultado esperado.

As Redes Neurais Artificiais (RNAs) surgem nesse caso com o intuito de facilitar a resolução deste tipo de problema. Esse método é baseado em um modelo matemático que procura simular a forma e o comportamento da estrutura neural biológica dos seres humanos. Facilitando assim, a resolução de uma enorme variedade de problemas complexos com uma grande precisão.

Dentro desse contexto, o objetivo deste trabalho é utilizar as RNAs para se calcular as propriedades termodinâmicas da água a partir de dados da velocidade do som, temperatura e pressão. Além disso, avaliar qual a melhor estrutura de RNA para desempenhar essa tarefa e testar a sua capacidade de interpolação.

\section{MATERIAIS E MÉTODOS}

\subsection{Obtenção Dos Dados Experimentais}

Os dados termodinâmicos da água para o treinamento e simulação das RNAs foram obtidos dos artigos: The IAPWS formulation 1995 for the thermodynamic properties of ordinary water substance for general and scientific use (Wagner; Pruß, 2002) e A Fundamental Equation for Water Covering the Range from the Melting Line to $1273 \mathrm{~K}$ at Pressures up to $25000 \mathrm{MPa}$ (Saul; Wagner, 1989).

\subsection{Variáveis de Entrada e Saída}

Para o treinamento da rede foram utilizados os dados isotérmicos em 12 temperaturas diferentes, sendo elas $274 \mathrm{~K}, 365 \mathrm{~K}, 456 \mathrm{~K}, 547 \mathrm{~K}, 638 \mathrm{~K}, 729 \mathrm{~K}, 820 \mathrm{~K}, 911 \mathrm{~K}, 1002 \mathrm{~K}$, $1093 \mathrm{~K}, 1184 \mathrm{~K}$ e $1275 \mathrm{~K}$, e a pressão variando de $1 \mathrm{MPa}$ a $100 \mathrm{MPa}$, com um incremento de $1 \mathrm{MPa}$ para cada isoterma. A faixa de velocidade do som explorada foi de $387,48 \mathrm{~m} \cdot \mathrm{s}^{-1} \mathrm{a}$ $1735,2 \mathrm{~m} . \mathrm{s}^{-1}$. Essa faixa de temperatura e pressão englobam as fases vapor, líquido e fluido supercrítico. As variáveis de saída da rede foram a densidade e a capacidade calorífica a pressão constante $(\mathrm{Cp})$.

O número total de pontos apresentados para as RNAs na etapa de treinamento foram de 1234 , sendo $70 \%$ deles no treinamento, $15 \%$ na validação e $15 \%$ para nos testes. A divisão dos pontos foi aleatória e o treinamento das RNAs foi realizado utilizando-se do toolbox de RNAs do software MatLab®.

Em uma segunda etapa, utilizando-se da rede treinada foram realizadas simulações a partir de dados independentes do treinamento. Assim, foram utilizados dados isobáricos em 10 pressões diferentes, sendo elas $1 \mathrm{MPa}, 5 \mathrm{MPa}, 12,5 \mathrm{MPa}, 25 \mathrm{MPa}, 40 \mathrm{MPa}, 50 \mathrm{MPa}, 60$ $\mathrm{MPa}, 75 \mathrm{MPa}, 85 \mathrm{MPa}$ e $100 \mathrm{MPa}$, e abrangendo uma faixa de temperatura de 264,3 K a 1273 $\mathrm{K}$ para cada pressão, O número total de pontos apresentados para as RNA na etapa de simulação foram de 699. 


\subsection{Simulação}

A simulação consistiu de duas etapas, a primeira foi o treinamento, e a segunda, a simulação para uma avaliação da capacidade de interpolação da RNA. Na etapa de treinamento usou-se o método Levemberg-Marquardt como método de otimização, que minimiza a função objetivo, dada pela Equação (1). A função tangente hiperbólica foi empregada como função de ativação dos neurônios em todas as camadas. Foram testadas estruturas de RNAs com uma e duas camadas ocultas e variando-se a quantidade de neurônios de 5 a 35 .

$$
F_{a b j}=\sum_{i=1}^{m} \frac{\left(y-y^{\prime}\right)^{2}}{m}
$$

em que: y é o valor estimado pela rede, y'é o valor real fornecido à rede e $\mathrm{m}$ é o número de dados experimentais fornecidos a rede.

\section{RESULTADOS E DISCUSSÃO}

\subsection{Treinamento}

Os resultados são mostrados na Tabela 1 com os parâmetros a serem avaliados: $F_{\text {obj }}$ na validação, $\mathrm{F}_{\mathrm{obj}}$ no treinamento, $\mathrm{r}^{2}$ no treinamento, $\mathrm{r}^{2}$ na validação e $\mathrm{r}^{2}$ no teste.

Tabela 1. Tabela com as diferentes estruturas de RNAs testadas durante a etapa de treinamento com uma e duas camadas ocultas.

\begin{tabular}{cccccc}
\hline Estrutura & $F_{\text {obj validação }}$ & $F_{\text {obj }}$ treinamento & $r^{2}$ treinamento & $\mathbf{r}^{\mathbf{2}}$ validação & $\mathbf{r}^{\mathbf{2}}$ teste \\
\hline $3-5-2$ & $1,435 \times 10^{5}$ & $7,960 \times 10^{4}$ & 0,999 & 0,999 & 0,998 \\
$3-10-2$ & $2,500 \times 10^{8}$ & $1,980 \times 10^{8}$ & 0,757 & 0,703 & 0,731 \\
$3-30-2$ & $2,600 \times 10^{3}$ & $6,420 \times 10^{3}$ & 0,999 & 1,000 & 0,999 \\
$3-35-2$ & $3,400 \times 10^{8}$ & $3,880 \times 10^{8}$ & 0,478 & 0,545 & 0,513 \\
$3-10-5-2$ & $9,185 \times 10^{2}$ & $9,840 \times 10^{2}$ & 1,000 & 0,999 & 0,999 \\
$3-15-5-2$ & $2,400 \times 10^{8}$ & $2,340 \times 10^{8}$ & 0,746 & 0,706 & 0,747 \\
$3-20-15-2$ & $9,622 \times 10^{2}$ & $1,150 \times 10^{3}$ & 0,999 & 1,000 & 1,000 \\
$3-20-20-2$ & $7,000 \times 10^{7}$ & $9,000 \times 10^{7}$ & 0,908 & 0,920 & 0,870 \\
$3-30-20-2$ & $\mathbf{7 , 9 5 3}$ & $\mathbf{2 , 3 5 0}$ & $\mathbf{1 , 0 0 0}$ & $\mathbf{1 , 0 0 0}$ & $\mathbf{0 , 9 9 9}$ \\
$3-35-25-2$ & $7,262 \times 10^{4}$ & $8,900 \times 10^{2}$ & 1,000 & 0,999 & 0,999 \\
\hline
\end{tabular}

Segundo Nowruzi e Ghassemi (2016), um menor valor de $\mathrm{F}_{\mathrm{obj}}$ e um $\mathrm{r}^{2}$ mais próximo de 1 são indicativos para a escolha da melhor estrutura de uma RNA. Sendo assim, dentre as 
diversas configurações testadas, a melhor estrutura de rede que apresentou esses parâmetros foi a 3-30-20-2. Isso porque além dos $\mathrm{r}^{2}$ mais próximos de um, essa estrutura de rede com duas camadas ocultas apresentou um menor valor para a função objetivo. Este parâmetro, segundo Junior (2005), quando mais próximo de zero, menor o erro. Além disso, os dados de saída calculados pelas RNAs foram comparados com os valores de saída fornecidos as RNAs, gerando assim um erro médio para todas as estruturas analisadas (dados não apresentados). Para a estrutura 3-30-20-2, os erros médios calculados foram $0,7 \%$ e $0,1 \%$, para o Cp e a densidade, respectivamente.

A Figura 1 mostra o erro percentual para cada ponto experimental para a densidade. É possível observar que em grande parte dos pontos, os erros foram bem menores do que $1 \%$. Já a Figura 2 mostra o erro percentual de cada ponto experimental para o Cp, onde também se pode verificar que a faixa onde acontece a concentração dos erros é bem baixa, nesse caso, abaixo de $1 \%$.

Figura 1. Erro para a variável densidade.

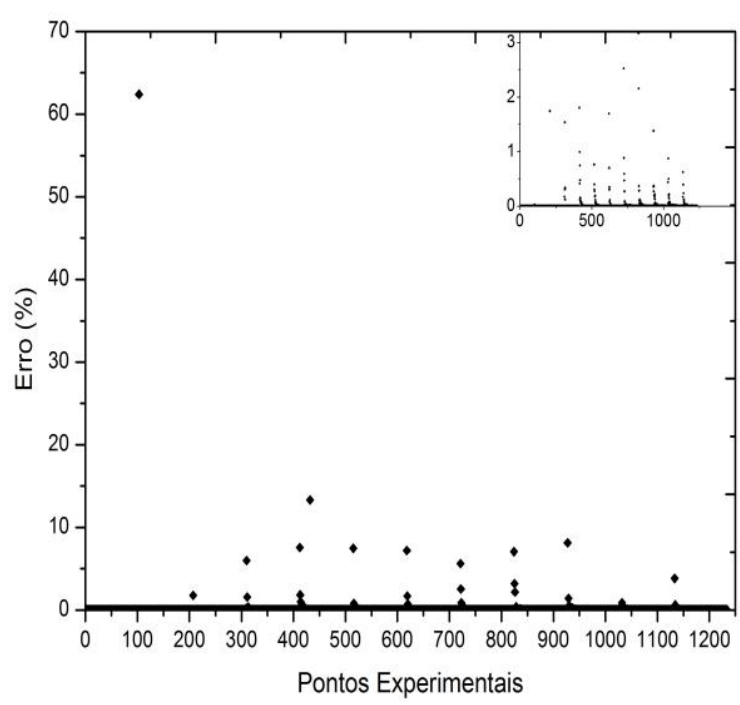

Figura 2. Erro para a variável cp.

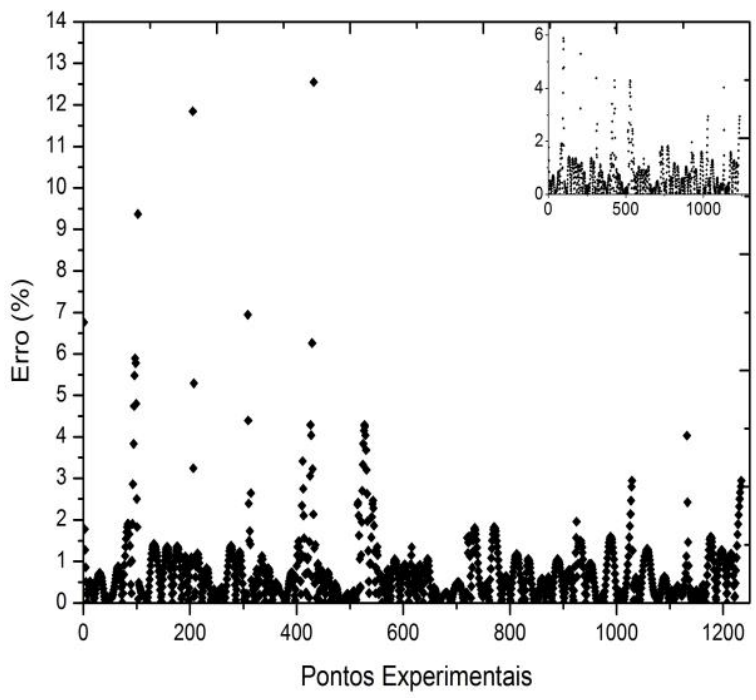

Os resultados do treinamento com o método Levemberg-Marquardt demonstram que esse método é eficiente ao realizar essa tarefa. Neste trabalho, o método Resilient BackPropagation também foi utilizado no treinamento das redes, mas seus resultados foram omitidos devido ao baixo desempenho observado. No trabalho de Da Cruz (2010) esse algoritmo também se mostrou mais eficaz em comparação com os demais, sempre convergindo para uma solução adequada.

\subsection{Simulação}

Com a RNA treinada, partiu-se para a etapa de simulação. Assim, gerou-se um conjunto de dados de saída que foram comparados com os dados coletados na literatura. Calculou-se, assim, o erro médio para cada um dos parâmetros testados. Os valores obtidos foram 3,21 \% para a densidade e 3,22 \% para a Cp. Observando-se estes valores, verifica-se 
que os resultados para a simulação foram satisfatórios, com erros baixos, comprovando a eficiência da estrutura de rede escolhida neste estudo.

A Figura 3 permite analisar os resultados da simulação para a densidade, avaliando a distribuição dos erros para todos os pontos experimentais. É possível visualizar que os erros se concentram em uma faixa de valores que podem ser considerados satisfatórios. Ainda, é possível verificar que há pontos em que os erros percentuais são consideráveis, chegando próximo a $175 \%$. No entanto nota-se que os erros estão distribuídos de forma mais homogênea na parte inferior do gráfico, onde também é evidente que a grande parte dos erros estão abaixo de $2,0 \%$.

Para uma análise da simulação referente ao Cp, plotou-se o gráfico da distribuição de erros para todos os pontos experimentais, presente na Figura 4. É possível verificar que os valores dos erros se encontram em uma faixa que pode ser considerada, também, satisfatória. Assim como para a densidade, também há valores de erros altos nesse caso. Mas é possível após análise que os erros se distribuem de forma mais homogênea na parte inferior do gráfico, onde a grande maioria dos erros concentrada abaixo de $2,0 \%$.

Ao se investigar a causa dos altos erros mencionados no parágrafo anterior, se observou que eles se concentravam nas condições de transições de fase. Isso provavelmente ocorreu porque na etapa de treinamento poucas regiões que envolviam o equilíbrio líquido-vapor foram apresentadas à RNA.

Figura 3. Erro para a variável densidade.

Figura 4. Erro para a variável cp.
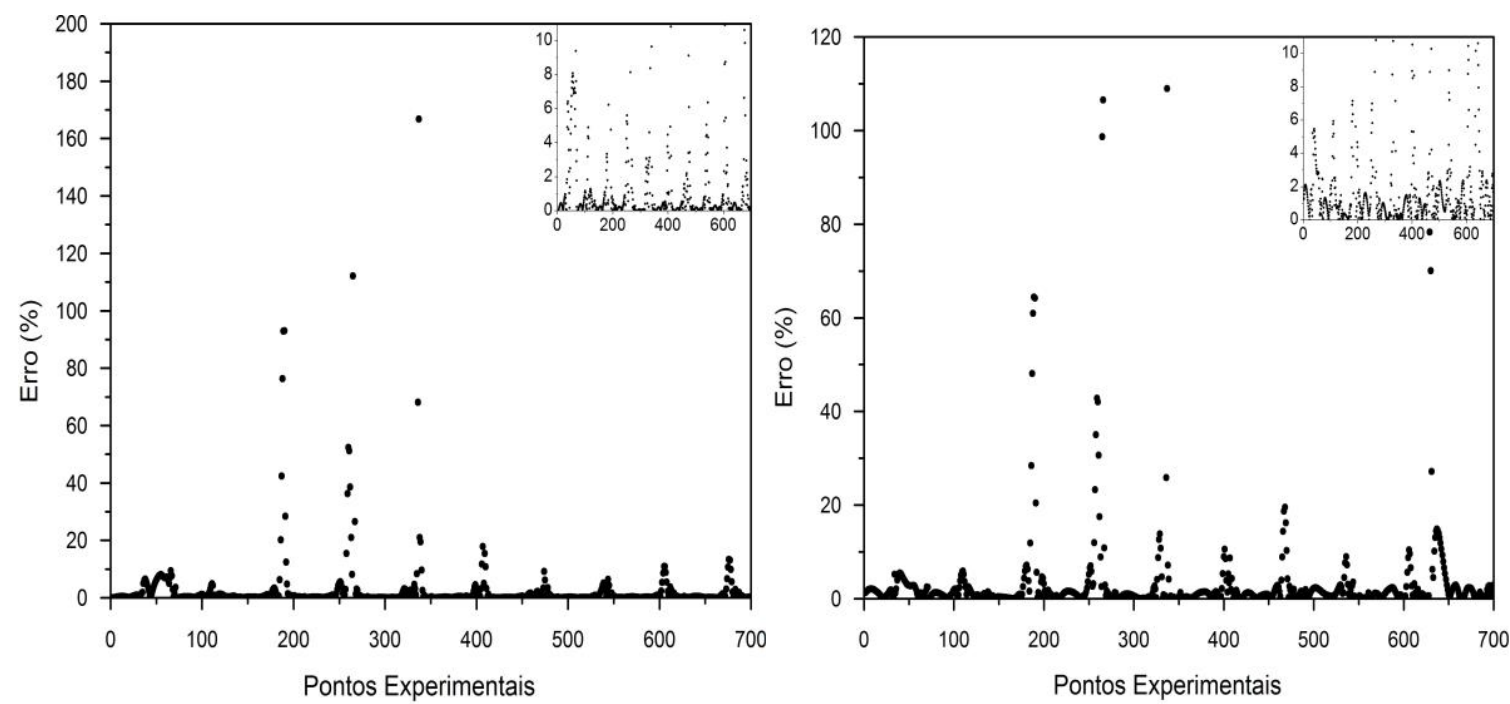

Benedetto et al. (2005) calcularam a densidade e o calor específico a pressão constante da água utilizando as equações diferenciais parciais de segunda ordem, com auxílio do método numérico Runge-Kutta. Os erros percentuais obtidos pelos autores foram da ordem de $0,1 \%$. A RNA deste trabalho consegue prever essas propriedades com erros na ordem de 3,0 \%. Apesar do desempenho da RNA ser matematicamente baixo, vale salientar que os resultados obtidos por Benedetto et al. (2005) estão dentro de uma faixa de temperatura que vai de $274 \mathrm{~K}$ a $394 \mathrm{~K}$, com apenas duas linhas isobáricas na região de fase líquida. Neste trabalho, o modelo obtido abrange uma faixa de temperatura muito extensa, pois vai de 264,3 
K a $1273 \mathrm{~K}$, para 10 linhas isobáricas, e engloba três diferentes estados: líquido, vapor, e fluido supercrítico.

Apesar de os erros alcançados por Benedetto et al. (2005) ter sido menores quando comparados aos obtidos pela RNA, este trabalho confirma que as RNAs podem ser uma alternativa viável ao cálculo das propriedades termodinâmicas da água a partir de medidas da velocidade do som. Vale salientar, que uma vez treinada, uma RNA se torna uma equação simples que relaciona as entradas e as saídas, ou seja, $f(x)=y$.

\section{CONCLUSÃO}

Este trabalho visava o cálculo de propriedades termodinâmicas via RNAs utilizando para isso a velocidade do som como um dos dados de entrada. A ferramenta utilizada para esse propósito se mostrou altamente eficaz, uma vez que solucionou os problemas com rapidez, eficiência e precisão. Os resultados obtidos durante o processo de treinamento se mostraram dentro dos critérios de avaliação para a estrutura de RNA escolhida. Os erros médios finais apresentados na etapa de simulação dos dados experimentais foram satisfatórios, demonstrando assim, a capacidade de aprendizado das RNAs.

\section{REFERÊNCIAS BIBLIOGRÁFICAS}

BENEDETTO, G.; GAVIOSO, R.; ALBO, P. G.; LAGO, S.; RIPA, D. M.; SPAGNOLO, R. Speed of Sound in Pure Water at Temperatures between 274 and 394áK and at Pressures up to 90áMPa. International journal of thermophysics, v. 26, n. 6, p. 1667-1680, 2005.

DA CRUZ, A. R. Análise de Componentes Principais e Classificaç ao via Rede Neural Multicamadas de Uma Base de Dados Extra1dos de Sinais Elétricos de Neurônios Visuais de Uma Coruja. Proceedings Seminário Interno da disciplina de Redes Neurais ArtificiaiS, p. 88, 2010.

JUNIOR, A. N. Aplicação de Redes Neurais utilizando o software MATLAB. 2005.

NOWRUZI, H.; GHASSEMI, H. Using artificial neural network to predict velocity of sound in liquid water as a function of ambient temperature, electrical and magnetic fields. Journal of Ocean Engineering and Science, v. 1, n. 3, p. 203-211, 2016.

SAUL, A.; WAGNER, W. A Fundamental Equation for Water Covering the Range from the Melting Line to $1273 \mathrm{~K}$ at Pressures up to $25000 \mathrm{MPa}$. Journal of Physical and Chemical Reference Data, v. 18, n. 4, p. 1537-1564, 1989.

WAGNER, W.; PRUß, A. The IAPWS formulation 1995 for the thermodynamic properties of ordinary water substance for general and scientific use. Journal of Physical and Chemical Reference Data, v. 31, n. 2, p. 387-535, 2002. 